$06 ; 13.1$

\title{
Рост полупроводниковых III-V гетероструктур на подложках SiC/Si
}

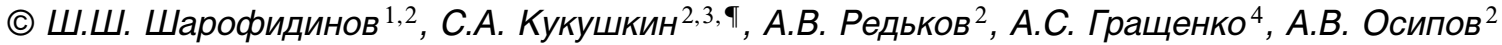 \\ ${ }^{1}$ Физико-технический институт им. А.Ф. Иофрфе РАН, Санкт-Петербург, Россия \\ ${ }^{2}$ Институт проблем машиноведения РАН, Санкт-Петербург, Россия \\ ${ }^{3}$ Санкт-Петербургский государственный политехнический университет Петра Великого, Санкт-Петербург,Россия \\ ${ }^{4}$ Санкт-Петербургский национальный исследовательский университет информационных технологий, механики и оптики \\ (Университет ИТМО), Санкт-Петербург, Россия \\ बE-mail: sergey.a.kukushkin@gmail.com
}

Поступило в Редакцию 17 апреля 2019г.

В окончательной редакции 17 апреля 2019г.

Принято к публикации 19 апреля 2019г.

Методом хлорид-гидридной эпитаксии на $\mathrm{Si}$ с буферным нанослоем $\mathrm{SiC}$ выращена гетероструктура, состоящая из трех толстых слоев: $\mathrm{AlN}$ (толщина $\sim 0.72 \mu \mathrm{m}$ ), $\mathrm{AlGaN}$ (толщина $\sim 1.82 \mu \mathrm{m}$ ) и $\mathrm{GaN}$ (толщина $\sim 2.2 \mu \mathrm{m}$ ). Выращенная гетероструктура исследована методом сканирующей электронной микроскопии, методом энергодисперсионного анализа и с помощью ряда других методик. Исследования показали, что использование подложек $\mathrm{SiC} / \mathrm{Si}$ позволяет выращивать пленки соединений III-V c высокой скоростью роста $(\sim 66 \mu \mathrm{m} / \mathrm{h})$ без трещин и с небольшими остаточными упругими напряжениями $(160 \mathrm{MPa})$.

Ключевые слова: эпитаксия, гетероструктуры, широкозонные полупроводники, HVPE, карбид кремния, нитрид алюминия, нитрид галлия.

DOI: 10.21883/PJTF.2019.14.48018.17841

Одной из актуальных задач электроники является совершенствование и удешевление методов нанесения бездефектных тонких пленок и гетероструктур полупроводников групп III-V: нитрида галлия $(\mathrm{GaN})$, нитрида алюминия (AlN), карбида кремния ( $\mathrm{SiC})$, а также их интеграция с существующей кремниевой технологией. Для решения этой задачи необходимо переходить к более высокопроизводительным методам нанесения и совместимым с кремнием подложкам, позволяющим растить подобные слои с малым количеством дефектов. В настоящей работе показано, что одним из путей решения этой задачи может быть использование метода хлорид-гидридной эпитаксии (HVPE), обеспечивающего высокие скорости роста пленок, совместно с гибридными подложками нано-SiC/Si, полученными методом замещения атомов $[1,2]$. Таким образом, основной целью работы является исследование гетероструктур GaN/AlGaN/AlN, выращенных методом HVPE на подложках нано-SiC/Si.

B качестве исходной подложки для нанесения слоя $\mathrm{SiC}$ использовались пластины кремния $p$-типа проводимости ориентации (111) с удельным сопротивлением $50 \Omega \cdot \mathrm{cm}^{-1}$, диаметром 2 дюйма и толщиной $0.35 \mathrm{~mm}$. Перед нанесением $\mathrm{SiC}$ они были обработаны по методике, детально описанной в [3]. В результате обработки был удален поверхностный слой оксида кремния, a также проведена пассивация поверхности кремния гидридными группами. Синтез подложки $\mathrm{SiC} / \mathrm{Si}$ осуществлялся в реакторе, конструкция которого, как и технология роста, детально описана в обзорах $[1,2]$. Использовались следующие условия синтеза: температура роста $1270^{\circ} \mathrm{C}$, общее давление в реакторе 2 Torr, поток газа $\mathrm{CO}-12 \mathrm{sccm}$, газа $\mathrm{SiH}_{4}-3.5 \mathrm{sccm}$, время синтеза $15 \mathrm{~min}$. Синтез последующих слоев III-нитридов методом HVPЕ проводился при условиях, представленных в таблице.

После процесса роста образцы были исследованы методами электронной микроскопии на микроскопе Tescan Lyra 3, оборудованном модулем дифракции обратно отраженных электронов и модулем энергодисперсионного анализа производства компании Oxford Instruments. На рис. 1 представлено полученное с помощью сканирующей электронной микроскопии (СЭМ) изображение скола выращенных слоев. Хорошо видна структура приповерхностной области кремния, которая содержит большое количество пор, появление которых связано с особенностями протекания твердотельной реакции кремния с газом СО при синтезе методом замещения атомов. Детальное описание этого явления и причин зарождения пор дано в обзорах [1,2]. Пористый слой помогает механически „развязать“ подложку и растущие на ней тонкие пленки и уменьшить упругие напряжения, возникающие в растущих слоях вследствие различий коэффициентов термического расширения и параметров решетки пленки и подложки. Структура этого пористого слоя, а также его временна́я эволюция при выращивании методом замещения атомов подробно исследованы в работах [4,5]. На СЭМ-изображении видны слои $\mathrm{GaN}, \mathrm{AlGaN}, \mathrm{AlN}$. Слой $\mathrm{SiC}$ ввиду его малой толщины представлен отдельно на вставке к рис. 1. Толщины слоев по данным электронной микроскопии были следующими: $\mathrm{GaN} \sim 2.2 \mu \mathrm{m}, \mathrm{AlGaN} \sim 1.82 \mu \mathrm{m}$, 
Условия синтеза слоев гетероструктуры GaN/AlGaN/AlN

\begin{tabular}{|c|c|c|c|c|c|c|}
\hline Слой & $\begin{array}{c}\text { Поток } \\
\text { Ar, } \\
\mathrm{ml} / \mathrm{min}\end{array}$ & $\begin{array}{c}\text { Поток } \\
\mathrm{NH}_{3}, \\
\mathrm{ml} / \mathrm{min}\end{array}$ & $\begin{array}{c}\text { Поток } \mathrm{HCl} \\
\text { (через } \mathrm{Ga}) \\
\text { ml/min }\end{array}$ & $\begin{array}{c}\text { Поток } \\
\mathrm{HCl} \\
\text { (через } \\
\mathrm{Al} \text { ), } \\
\mathrm{ml} / \mathrm{min}\end{array}$ & $\begin{array}{c}\text { Температура } \\
\text { роста, }{ }^{\circ} \mathrm{C}\end{array}$ & $\begin{array}{c}\text { Время } \\
\text { роста, min }\end{array}$ \\
\hline $\begin{array}{c}\mathrm{AlN} \\
\mathrm{AlGaN} \\
\mathrm{GaN}\end{array}$ & 4 & 1.5 & $\begin{array}{c}0 \\
100 \\
100\end{array}$ & $\begin{array}{c}200 \\
200 \\
0\end{array}$ & 1050 & $\begin{array}{l}1 \\
3 \\
2\end{array}$ \\
\hline
\end{tabular}

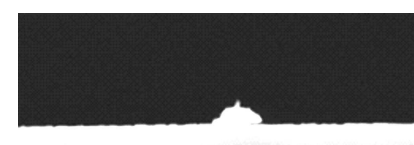

$\mathrm{GaN}$

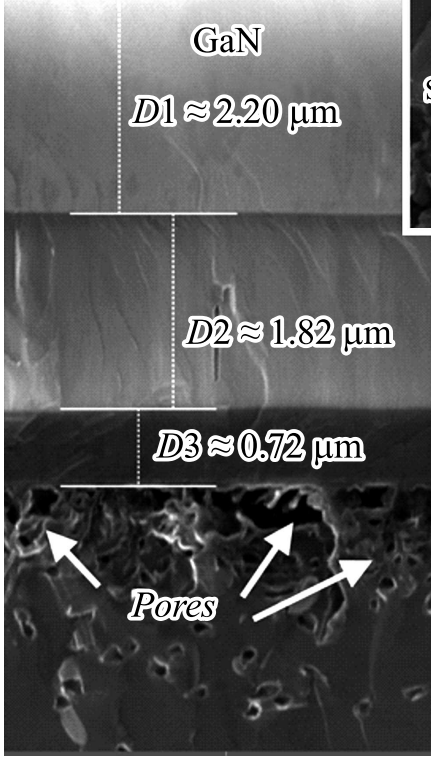

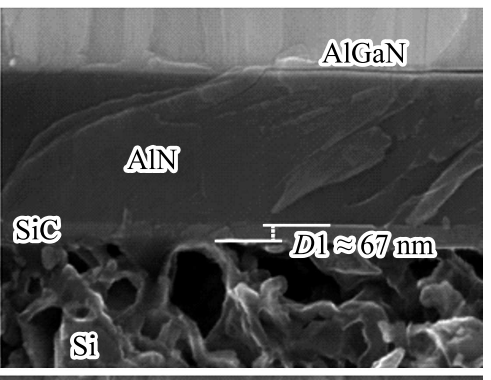

$\mathrm{Si}$
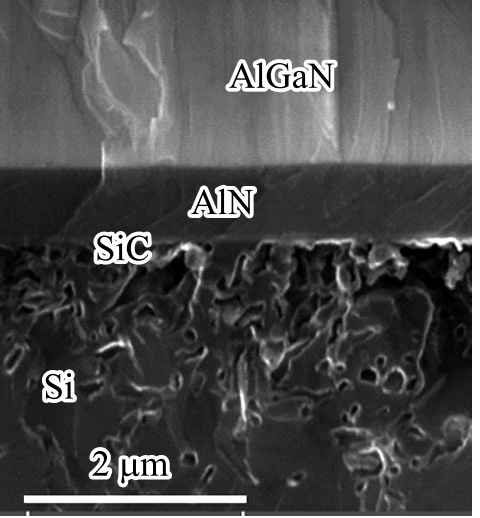

Рис. 1. СЭМ-изображение скола структуры $\mathrm{GaN} / \mathrm{AlGaN} / \mathrm{AlN} / \mathrm{SiC} / \mathrm{Si}$. На вставке представлено увеличенное изображение слоя $\mathrm{SiC}$.

$\mathrm{AlN} \sim 0.72 \mu \mathrm{m}, \mathrm{SiC} \sim 70 \mathrm{~nm}$. Отметим, что исходя из данных о времени синтеза (см. таблицу) общая скорость роста слоя AlN составила $42 \mu \mathrm{m} / \mathrm{h}$, слоя $\mathrm{AlGaN}-$ $36 \mu \mathrm{m} / \mathrm{h}$, тогда как для слоя $\mathrm{GaN}$ она была равна $66 \mu \mathrm{m} / \mathrm{h}$. Также следует отметить, что рост AlGaN, по всей видимости, в данном режиме ограничен скоростью последовательного встраивания адатомов Al и Ga в решетку, поскольку суммарный поток исходных реагентов при росте $\mathrm{AlGaN}$ больше, чем при росте слоев AlN и GaN, тогда как скорость роста, наоборот, меньше.

Поверхность образца была изучена методом дифракции обратно отраженных электронов. Типичная картина дифракции представлена на рис. 2, на котором также обозначены идентифицированные рефлексы. Картирование образца вдоль поверхности показало, что дифракционная картина идентична на различных участках образца и пленка $\mathrm{GaN}$ является монокристаллической. Анализ картины дифракции позволил заключить, что пленка имеет гексагональную структуру с осью c, ориентированной перпендикулярно поверхности, т.е. является полярной.

Методом энергодисперсионного анализа скола образца был изучен элементный состав слоев. Анализ показал, что слои $\mathrm{GaN}$ и $\mathrm{AlN}$ являются стехиометрическими в пределах погрешности прибора, а в слое $\mathrm{AlGaN}$ доли атомов $\mathrm{Al}, \mathrm{Ga}$ и $\mathrm{N}$ составляют 11.5, 38.5 и 50 at.\% соответственно. На рис. 3, $а$ представлены полученные зависимости атомной доли алюминия, галлия и азота от глубины. Необходимо обратить внимание на некоторое уменьшение доли галлия и увеличение доли алюминия вблизи интерфейса слоев $\mathrm{GaN} / \mathrm{AlGaN}$, которое может быть обусловлено особенностями методики измерения, так как на границе слоев наблюдается неоднородность рельефа, которая могла исказить получаемые данные.

На рис. 3, $b$ представлен рамановский спектр полученной гетероструктуры, измеренный с помощью кон- 
фокального рамановского микроскопа Witec Alpha 300R. Измерения проводились с использованием объектива 10x в геометрии обратного рассеяния. При использовании объектива $10 \mathrm{x}$ вертикальный размер стяжки сфокусированного пучка составляет несколько микрометров, и таким образом в фокусе находятся все слои и подложка одновременно, что и демонстрирует приведенный спектр. Так, на нем хорошо видны линии кремния $\left(520,300 \mathrm{~cm}^{-1}\right)[6]$, линия карбида кремния $\left(796 \mathrm{~cm}^{-1}\right)$ [7], линия нитрида алюминия $\left(657 \mathrm{~cm}^{-1}\right)$ [8] и линии нитрида галлия $\left(568,144 \mathrm{~cm}^{-1}\right)$ [8]. На вставке детально представлена область спектра около $568 \mathrm{~cm}^{-1}$, которая, как показывает разложение, хорошо описывается двумя отдельными линиями. Одна из этих линий имеет спектральное положение $\sim 568.1 \mathrm{~cm}^{-1}$ и ширину на полувысоте (FWHM) около $5 \mathrm{~cm}^{-1}$, тогда как у другой, более широкой, спектральное положение $572.3 \mathrm{~cm}^{-1}$ и $\mathrm{FWHM} 8 \mathrm{~cm}^{-1}$. Первую линию можно отнести к верхнему слою $\mathrm{GaN}$, который, судя по спектральному положению, близок к объемному кристаллу $\left(567.4 \mathrm{~cm}^{-1}\right)[9]$ и незначительно упруго напряжен. Так, согласно формуле, приведенной в работе [9], упругие напряжения в слое $\mathrm{GaN}$ составляют $\sim 160 \mathrm{MPa}$. Вторая линия соответствует слою, представляющему твердый раствор AlGaN. Согласно [10], именно такое спектральное положение $\left(572 \mathrm{~cm}^{-1}\right)$ должна иметь линия $E_{2}$ у ненапряженного слоя с составом $\mathrm{Al}_{0.2} \mathrm{Ga}_{0.8} \mathrm{~N}$. Таким образом, рамановская спектроскопия, во-первых, подтверждает композицию состава слоя и, во-вторых, показывает, что выращенные на подложке $\mathrm{SiC} / \mathrm{Si}$ слои лишь незначительно упруго напряжены.

Проведенные исследования дают основания полагать, что подложки нано-SiC/Si могут быть использованы для выращивания толстых слоев (единицы-десятки микрометров) и гетероструктур полупроводников групп III-V с большой скоростью и, таким образом, пригодны

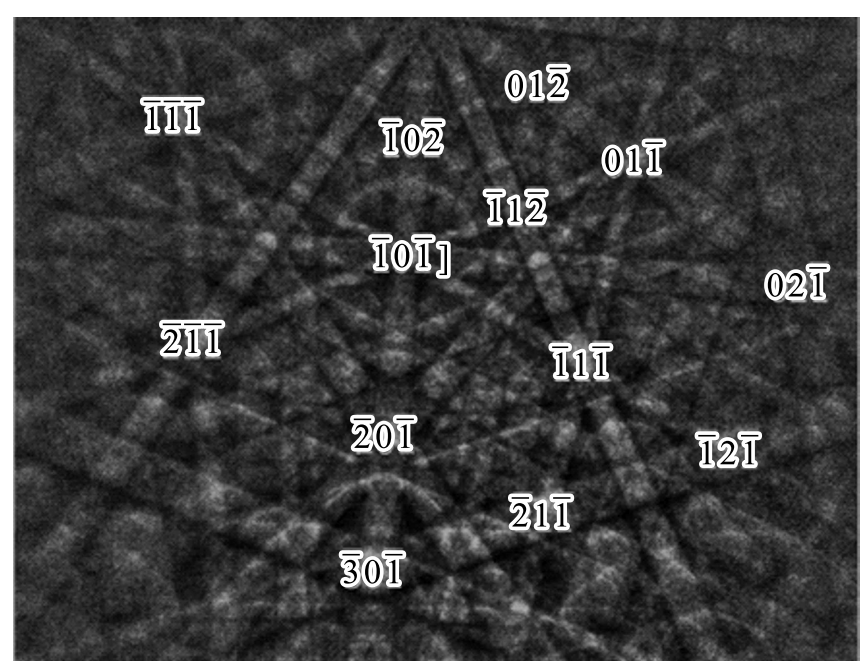

Рис. 2. Картина дифракции электронов, обратно отраженных от поверхности образца.

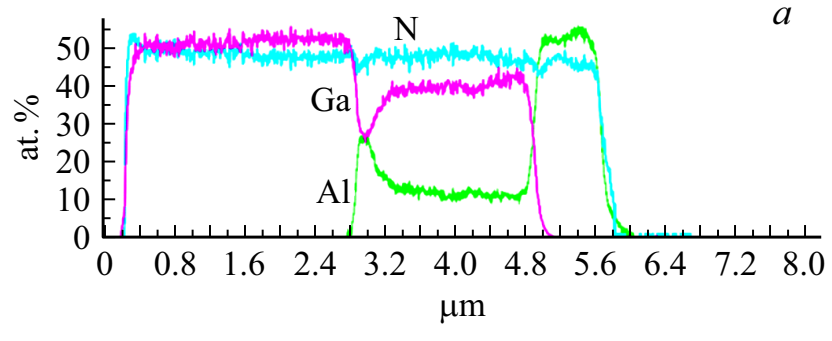

$b$

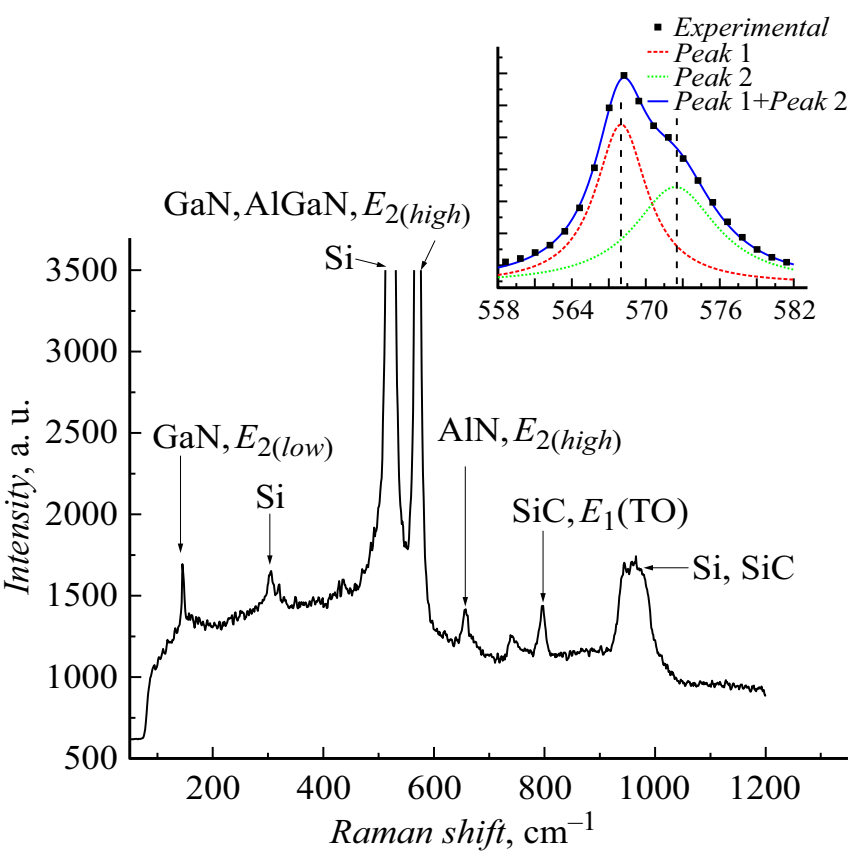

Рис. 3. Профили элементного состава образца по глубине, измеренные на сколе образца $(a)$, и рамановский спектр образца $(b)$. На вставке представлено разложение спектра в области $568 \mathrm{~cm}^{-1}$ на две линии.

для создания приборной компонентной базы нового поколения на основе широкозонных полупроводников, выращенных на кремнии без использования сапфира или дорогостоящих подложек объемного карбида кремния.

\section{Благодарности}

Исследования проводились с использованием оборудования уникальной научной установки „Физика, химия и механика кристаллов и тонких пленок“ ФГУП ИПМаш РАН (Санкт-Петербург).

Авторы выражают благодарность П.А. Сомову из демонстрационной лаборатории ООО „Тескан“ за содействие в электронно-микроскопических исследованиях.

\section{Конфликт интересов}

Авторы заявляют, что у них нет конфликта интересов. 


\section{Список литературы}

[1] Kukushkin S.A., Osipov A.V. // J. Phys. D: Appl. Phys. 2014. V. 47. N 31. P. 31300.

[2] Кукушкин С.А., Осипов А.В., Феоктистов Н.А. // ФТТ. 2014. T. 56. B. 8. C. $1457-1485$.

[3] Калинкин И.П., Кукушкин С.А., Осипов А.В. // ФТП. 2018. T. 52. B. 6. C. 656-663.

[4] Редьков А.В., Гращенко А.С., Кукушкин С.А., Осипов А.В., Котляр К.П., Лихачев А.И., Нащекин А.В., Сочников И.П. // ФТТ. 2019. Т. 61. В. 3. С. 433-440.

[5] Kukushkin S.A., Mizerov A.M., Osipov A.V., Redkov A.V., Timoshnev S.N. // Thin Solid Films. 2018. V. 646. P. 158162.

[6] Temple P.A., Hathaway C.E. // Phys. Rev. B. 1973. V. 7. N 8. P. 3685-3996.

[7] Nakashima S.I., Harima H. // Phys. Status Solidi A. 1997. V. 162. N 1. P. 39-64.

[8] Davydov V.Y., Kitaev Y.E., Goncharuk I.N., Smirnov A.N., Graul J., Semchinova O., Evarestov R.A. // Phys. Rev. B. 1998. V. 58. N 19. P. 12899.

[9] Tripathy S., Chua S.J., Chen P., Miao Z.L. // J. Appl. Phys. 2002. V. 92. N 7. P. 3503-3510.

[10] Bergman L., Bremser M.D., Perry W.G., Davis R.F., Dutta M., Nemanich R.J. // Appl. Phys. Lett. 1997. V. 71. N 15. P. 2157 2159. 